\title{
Estrategias de talla en Cueva Corazón (Mave, Palencia). Un yacimiento del Musteriense Antiguo en las estribaciones meridionales de la Cordillera Cantábrica
}

\author{
Knapping strategies at Cueva Corazón (Mave, Palencia). An Early Mousterian \\ site on the Southern foothills of the Cantabrian Range
}

\author{
Policarpo Sánchez Yustos (*) \\ Fernando Díez Martín (*) \\ Isabel M. ${ }^{a}$ Díaz Muñoz (**) \\ Diana Gómez de la Rúa (*) \\ José Ángel Gómez González (***)
}

\section{RESUMEN}

Este artículo estudia el registro lítico de Cueva Corazón en el marco de un proyecto de investigación iniciado en 2005. Hemos detectado una variedad y alargamiento de cadenas operativas líticas, frecuentemente fragmentadas, y una elevada estandarización tecnológica asociada a elaboradas estrategias de captación de materias primas de buena calidad. Este hecho permite inferir una complejidad de las redes territoriales y sociales. Por otro lado, su cronología y posición estratégica hacen de este enclave un lugar excepcional para conocer el Musteriense antiguo en ambos lados de la cordillera cantábrica.

\begin{abstract}
This article presents a study of the lithic record recently retrieved from Cueva Corazón in the context of a new research projects initiated in 2005. We have detected a variety of long, albeit highly fragmented, operational sequences. A remarkable technological standardization has also been observed, a trait clearly related to the use of good quality raw materials. These observations allow the inference of a complex web of territorial and social
\end{abstract}

(*) Universidad de Valladolid. Dpto. de Prehistoria y Arqueología. Plaza del Campus s/n. 47011 Valladolid. Correos e.: policarpos@hotmail.com;

fernando.diez.martin@uva.es; dianagoru@gmail.com

(**) C/ Rastrojo 3, 2. ${ }^{\circ}$ b. 470014 Valladolid. Correo e.: isabeldiazmunoz@yahoo.es

(***) Agencia Estatal de Meteorología. 47620 Villanubla. Valladolid. Correo e.: jagomgom@hotmail.com

Recibido: 31-V-2010; aceptado: 15-VII-2010. interactions. Moreover, Cueva Corazón, due to its chronology and strategic location, can become a future reference point for the study of the Early Mousterian on both sides of the Cantabrian Range.

Palabras Clave: Paleolítico antiguo; Achelense; Musteriense; Cuenca del Duero; Cordillera Cantábrica; Neandertales.

Key words: Ancient Palaeolithic; Acheulean; Mousterian; Duero Basin; Cantabrian Range; Neanderthals.

\section{PRESENTACIÓN}

Cueva Corazón está emplazada en un paredón calizo cortado por el río Pisuerga conocido como Cañón de la Horadada (Fig. 1). Esta región del noreste palentino es uno de los contrafuertes orientales de las estribaciones meridionales de la Cordillera Cantábrica. Significa el paso de las formas simples y horizontales de las campiñas de la cuenca del Duero a los realces montañosos donde destacan enérgicas crestas calizas. Forma parte de un heterogéneo y dinámico paisaje modelado por la intersección de varios dominios peninsulares: el cantábrico, el normeseteño y la cuenca alta del Ebro. Se trata por tanto de un auténtico ecotono tapizado por un mosaico medioambiental rico en biodiversidad. Además de la riqueza ecológica circundante, el Cañón de la Horadada goza de una importante posición estratégica, puesto que es un destacado hito paisajístico 


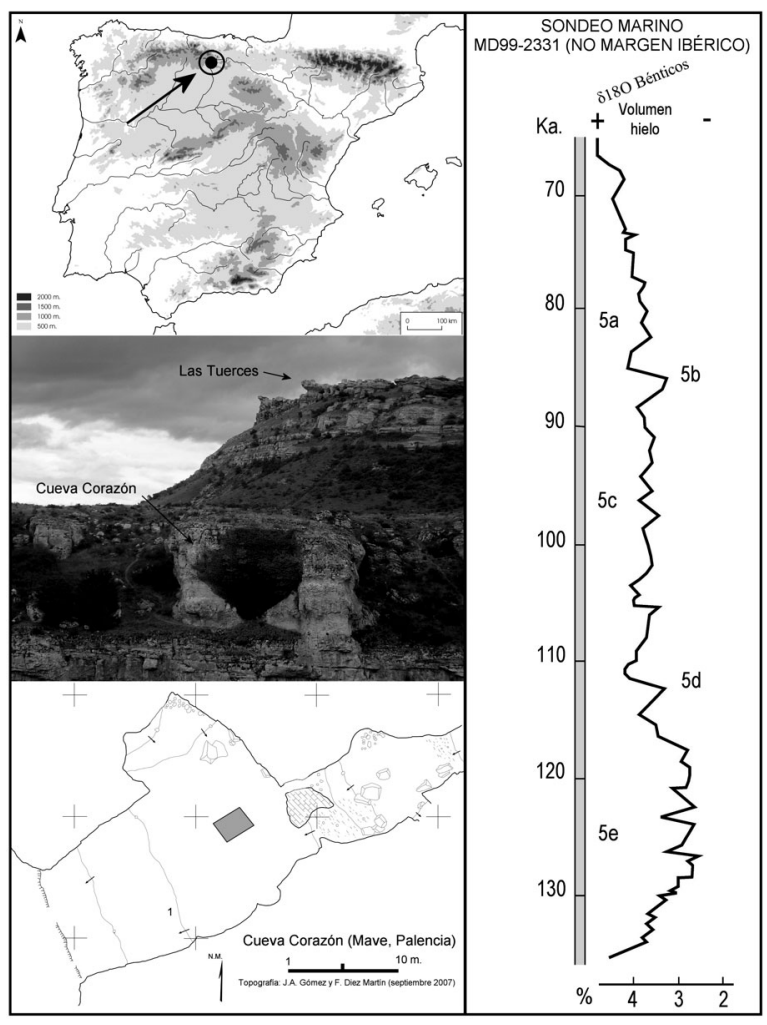

Fig. 1. Localización, planta y contexto paleoclimático de Cueva Corazón (Mave, Palencia), yacimiento del Musteriense antiguo.

dentro del corredor natural que conecta la Meseta con la Costa Cantábrica.

Este desfiladero horadado por numerosas cavidades, desde un punto de vista geológico, pertenece a la región vasco-cantábrica del gran Dominio Preasturiano. Estructuralmente corresponde al flanco occidental del sinclinal de la Lora de la Tuerce (Fig. 1), que da nombre a esta región, que a su vez está integrado en la gran estructura geomorfológica de la Plataforma Burgalesa, compuesta por las Loras de Valdivia (Palencia) y la Pata del Cid (Burgos) (Alcalde Crespo 1992). En estas elevadas plataformas mesozoicas de Las Loras se desarrollan unas estructuras sinclinales donde los supuestos valles son en realidad combes de inversión, depresiones que se corresponden a núcleos anticlinales vaciados y excavados por debajo de las charnelas sinclinales culminantes, y en la que los aparentes páramos son sinclinales colgados tipo Lora. Esta última puede definirse como una estructura sinclinal cisarmónica en sus flancos y con culminación plana en forma de muela.
El Museo Provincial de Palencia programa en 1978 la primera intervención arqueológica en las cavidades de la Horadada dirigida por el arqueólogo M. Santonja. Entre otras cavidades, se intervine en Cueva Corazón, donde se abre un sondeo de 4 $\mathrm{m}^{2}$ que depara varios fragmentos óseos y 17 objetos líticos identificados como musterienses (Santonja et al. 1982: 391; Santonja y Querol 1981).

En 2005, en el marco de un nuevo proyecto de investigación iniciado desde la Universidad de Valladolid, comienza una nueva ronda de excavaciones que intenta reconocer la totalidad de la secuencia estratigráfica y su potencial arqueológico. En el fondo de la espaciosa sala de acceso se abre una extensión de $6 \mathrm{~m}^{2}$ y en 2007 se amplía a $8 \mathrm{~m}^{2}$ (Fig. 1). Este sondeo exploratorio ha concretado la siguiente columna estratigráfica, de techo a muro: (N1) suelo removido de arcilla y arenas $(20 \mathrm{~cm})$, con restos romanos y altomedievales; (N2) arcillas marrones con abundantes clastos calizos, de potencia variable $(35$ y $110 \mathrm{~cm})$ debido a un acusado buzamiento orientado hacia el interior de la cavidad, en él se localizan todos los restos pleistocenos recuperados; (N3) $20 \mathrm{~cm}$ de finas arenas anaranjadas; (N4) costra estalagmítica; (N5) arcillas endokársticas muy plásticas de color marrón.

En el Nivel 2, aparte de una nutrida colección de fósiles, se han recuperado 149 objetos líticos $\left(18,6\right.$ piezas $\left./ \mathrm{m}^{2}\right)$, algunos con evidentes signos de alteración térmica. Se enviaron dos muestras de cuarcitas termoalteradas al Laboratorio de Datación y Radioquímica de la Universidad Autónoma de Madrid, obteniendo las siguientes dataciones por TL: $96.567 \pm 7.806$ y $95.763 \pm 7.456 \mathrm{ka}$ AP.

\section{REGISTRO LÍTICO}

\subsection{Datos generales}

Hasta el momento, la colección lítica de Cueva Corazón consta de 149 objetos. En las materias primas domina la cuarcita $(81,1 \%)$, seguida de lejos por el sílex $(10,3 \%)$, el cuarzo $(6,6 \%)$ y la caliza (Tab. 1). Se observa una clara selección (1) de cantos de cuarcita y cuarzo de grano medio y fino. Se puede distinguir hasta cinco va-

(1) La selección parece evidente pues en las terrazas del Pisuerga visitadas, próximas al yacimiento, este tipo de calidades faltan o su presencia es muy sumaria. 


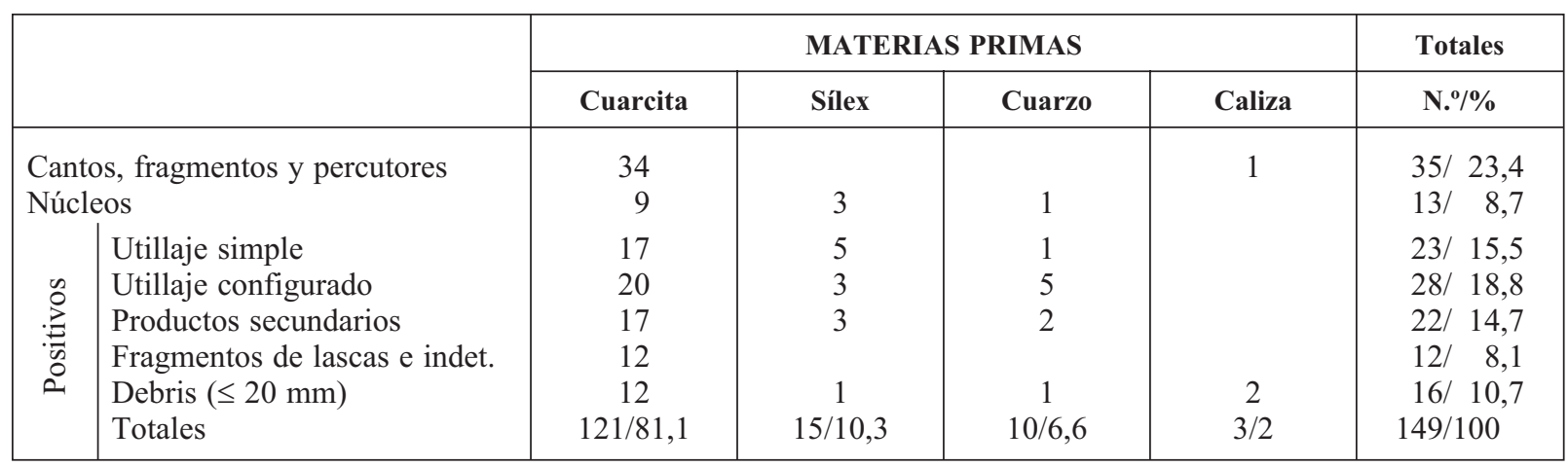

Tab. 1. Categorías de objetos según materias primas en Cueva Corazón (Mave, Palencia), yacimiento del Musteriense antiguo.

riedades de sílex en función de su color (negro, blanco, azul, traslúcido y achocolatado).

A la espera de un exhaustivo programa petrológico, poco podemos precisar sobre las variedades litológicas y los lugares de captación. Con todo, la superficie original conservada en algunos implementos de cuarcita y cuarzo apuntan a depósitos aluvionales y coluvionales. El sílex, presumiblemente, es captado en depósitos primarios, aunque en ocasiones lo mismo podría suceder con la cuarcita y el cuarzo. Por el contrario, la escasísima caliza empleada bien pudo conseguirse en el interior de la cavidad.

Las alteraciones más recurrentes son de orden térmico y resultan de actividades de calentamiento y combustión. Siempre están asociadas a cantos brutos de cuarcita. El $16 \%(n=24)$ de los objetos registrados las muestran. Este porcentaje podría aumentar levemente si incorporamos a esta categoría 3 cantos fragmentados, por causas difíciles de precisar.

Todos los objetos termoalterados son de una cuarcita de baja calidad, pues presentan numerosas diaclasas (2) y una granulometría más grosera que las empleadas en las labores de talla. Deducimos que su área de aprovisionamiento está próxima. De hecho, es probable que para dichas actividades se aprovecharan los nódulos cuarcíticos que alberga la propia cavidad.

Los 4 percutores $(109,143$ y 316 g), uno de ellos de caliza (566 g), y el yunque recuperado

(2) Por estas diaclasas suelen abrirse los cantos sometidos al calor intenso de un fuego, según hemos podido comprobar en numerosas experimentaciones y programas específicos de investigación; Gómez de la Rúa, D. 2006: Estudio de las rocas metamórficas termoalteradas de los yacimientos paleolíticos del Páramo de Quintanilla de Arriba, Valladolid. Tesis de licenciatura, inédita. Universidad de Valladolid. Valladolid.
(1031 g) son de cuarcitas de mayor calidad que los cantos y fragmentos anteriores. Aparentemente no muestran líneas de debilidad y su grano es más fino tal y como advierte su corteza. En esta calidad también se han documentado 3 cantos (sin estigmas ni termoalteraciones) que pudieron ser aportados como remanente de materia y/o como futuros percutores $(147,230$ y $254 \mathrm{~g})$.

De los 13 núcleos consignados, 9 son de cuarcita, 3 de sílex y 1 de cuarzo (Tab. 1). Destacamos por su singularidad un núcleo de cuarcita $a d$ hoc para punta $(564 \mathrm{~g})$. El dato más significativo de los productos de lascado es su sobresaliente representación (101 objetos que suman el 67,7\% del total de la colección). En esta última categoría distinguimos entre productos principales (utillaje), secundarios (subproductos), fragmentos de lasca (que no lascas fragmentadas), fragmentos indeterminados y restos de talla (debris) (Tab. 1).

Los productos principales son las lascas destinadas a ser útiles y, generalmente, están vinculadas a la fase de consumo. En este grupo diferenciamos entre el utillaje simple (sin transformar) y el utillaje configurado. En cambio, los productos secundarios son las lascas que están relacionadas con la fase de producción del utillaje: variados productos de descortezado, de acondicionamiento y lascas predeterminantes levallois. No descartamos que alguno de estos objetos haya sido empleado como utillaje.

En la figura 2A se aprecia con claridad cómo el tamaño del utillaje, por regla general, es superior al de los subproductos. De forma preferente, se seleccionan lascas de mayor tamaño para ser configuradas. Estos parámetros tipométricos deben ser matizados en función de las estrategias de producción (Fig. 2B). Llama la atención cómo la 

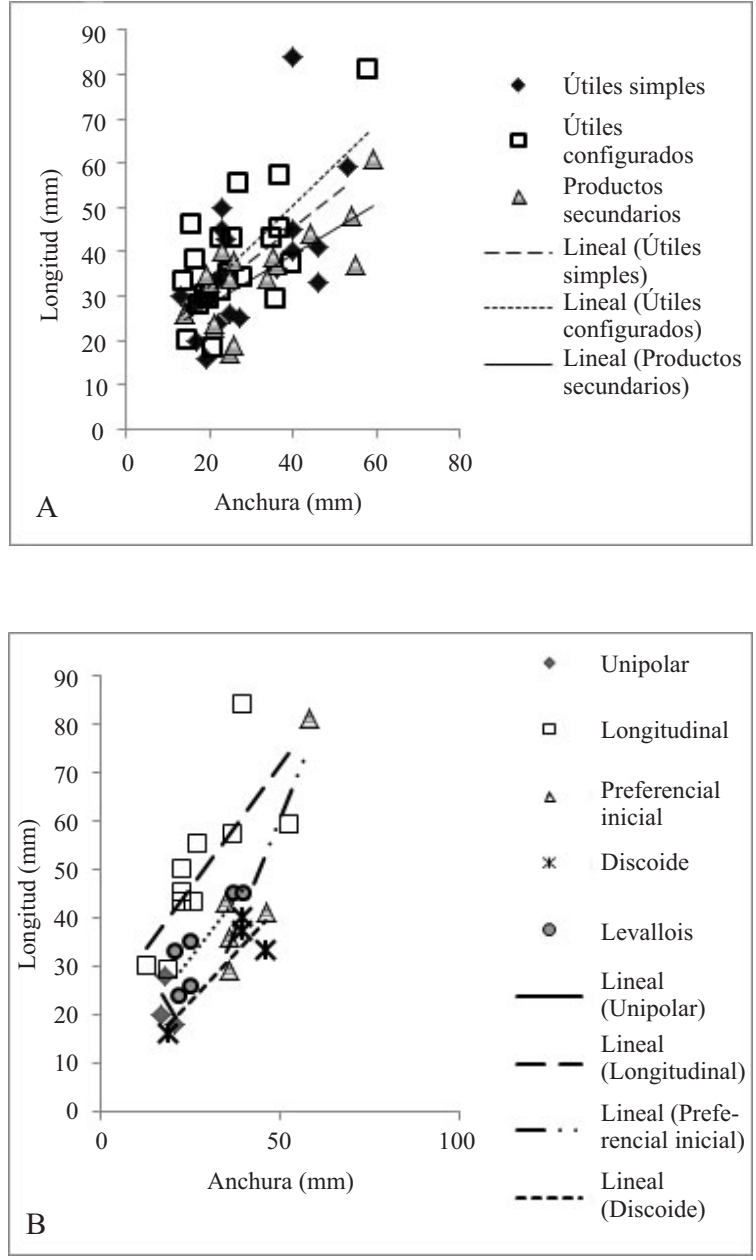

Fig. 2. Cueva Corazón (Mave, Palencia), yacimiento del Musteriense antiguo. A. Diagrama de dispersión (longitud y anchura) en los útiles y productos secundarios. B. Diagrama de dispersión (longitud y anchura) en los útiles según estrategias de talla.

mayoría del utillaje en cuarzo está configurado, mientras que en cuarcita y sílex las diferencias entre los productos no son tan acusadas (Tab. 1).

Entre las 28 lascas retocadas no se detecta ninguna asociación significativa entre morfotipos, sistemas de explotación y morfología. Por ejemplo, las raederas, que son el esquema de configuración más recurrente (Tab. 2), están elaboradas sobre soportes obtenidos de todas las estrategias de talla documentadas. En términos generales, abunda el utillaje reservado a diligencias de corte, aunque también son frecuentes las lascas destinadas a la punción, como así lo demuestra el variado repertorio de puntas (levallois y pseudolevallois), perfora-

\begin{tabular}{|l|r|r|}
\hline \multicolumn{1}{|c|}{ Morfotipos } & \multicolumn{2}{c|}{ Totales } \\
\hline Raederas & 10 & $13 / 46,6$ \\
$\quad$ Lateral & 2 & \\
$\quad$ Lateral doble & 1 & \\
$\quad$ Latero-transversal & & $4 / 14,2$ \\
Denticulados & & $3 / 10,7$ \\
Perforadores & & $1 / 3,6$ \\
Tranchet & & $2 / 7,1$ \\
Puntas & 1 & \\
$\quad$ Denticulada & 1 & \\
$\quad$ Levallois & & $2 / 7,1$ \\
Útiles compuestos & 1 & \\
$\quad$ Raedera lateral + perforador & 1 & \\
$\quad$ Denticulado + perforador & & $3 / 10,7$ \\
Lascas con retoque & &
\end{tabular}

Tab. 2. Número y contribución porcentual de los morfotipos reconocidos en Cueva Corazón (Mave, Palencia), yacimiento del Musteriense antiguo.

dores y diversos instrumentos con secciones punzantes destacadas mediante retoque.

En función de varios parámetros tecnomorfológicos observados en núcleos y lascas hemos podido reconstruir los sistemas de talla principales implicados en la producción. Distinguimos entre dos grandes esquemas operativos, cada uno compuesto por dos modalidades: unifacial inidireccional (unipolar y longitudinal) y bifacial centrípeto (discoide y levallois) (Fig. 3). La estrategia levallois y longitudinal, por este orden, son las más representadas. Esta diferencia responde a que la talla levallois se lleva a cabo en sílex y en cuarcita, mientras que la estrategia longitudinal únicamente en cuarcita (Tab. 3).

\subsection{Estrategias de talla y cadenas operativas}

Las materias primas que se gestionan bajo la estrategia unifacial unidireccional son el cuarzo y la cuarcita. En sus dos modalidades, la estrategia longitudinal, en contraposición a la unipolar, se caracteriza por una reducción del soporte en el sentido de su eje mayor, un acondicionamiento de la plataforma de golpeo, un ángulo paralelo de las superficies de lascado y una mayor producción ordenada en series longitudinales equidistantes. Así, la estrategia longitudinal genera productos de estructura alargada, mientras que la talla unipolar 


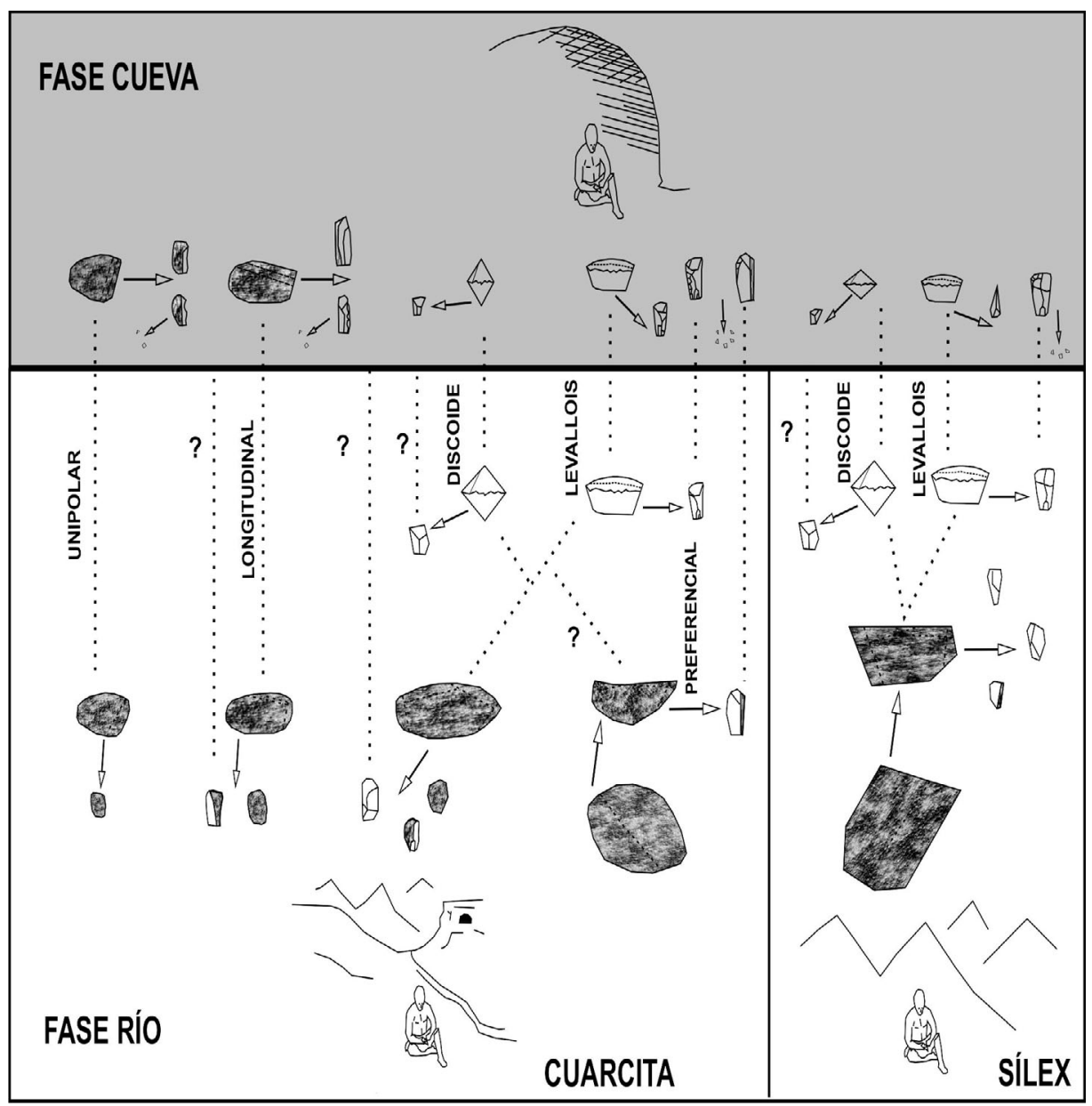

Fig. 3. Secuencia operativa y espacial de las estrategias de talla en Cueva Corazón (Mave, Palencia), yacimiento del Musteriense antiguo.

produce lascas más cortas y anchas (Fig. 2 B). Probablemente muchos de estos últimos productos tienen como matriz una lasca o fragmento. Si bien esta afirmación debe ser matizada a partir de la relación que se establece entre el sistema de explotación y la materia prima (Tab. 3).

\begin{tabular}{|l|c|c|c|c|}
\hline & Cuarcita & Sílex & Cuarzo & Totales \\
\hline Unipolar & 2 & & 4 & $6(14 \%)$ \\
Longitudinal & 11 & & & $11(25,6 \%)$ \\
Pref. Inicial & 7 & & & $7(16,3 \%)$ \\
Dicoide & 3 & 1 & & $4(9,4 \%)$ \\
Levallois & 11 & 4 & & $15(34,9 \%)$ \\
\hline
\end{tabular}

Tab. 3. Estrategias de talla en el utillaje según materias primas en Cueva Corazón (Mave, Palencia), yacimiento del Musteriense antiguo.
En cuarzo se ha registrado un núcleo sobre lasca cuyo grosor es explotado a partir de un esquema de reducción unipolar (33 g). Probablemente gran parte de las lascas de este material tienen este tipo de matriz. En cuarcita, el esquema unipolar, registrado en 2 núcleos ( 87 y 343 g), se caracteriza por la gestión del grosor del soporte mediante series cortas de extracciones semiabruptas. El sistema longitudinal también está representado por 2 núcleos, uno sobre canto $(335 \mathrm{~g})$ y otro sobre un fragmento de canto roto por una diaclasa (46 g).

Gran parte de las lascas vinculadas con las estrategias unidireccionales son de semidescortezado. También hay, aunque escasos, productos de plena producción longitudinal sin corteza dorsal. En los talones abundan los corticales, mientras que el resto son lisos. 
Las cadenas operativas de la estrategia unipolar se han acometido casi por completo en la propia cavidad ("fase cueva"). En el cuarzo domina este modelo productivo. Las primeras etapas se inician en el lugar de aprovisionamiento ("fase río"), al menos para extraer una lasca-matriz que posteriormente es introducida en el yacimiento (Fig. 3). La mayor parte de sus pequeñas lascas han sido retocadas (Tab. 1).

La producción longitudinal muestra una estrategia operativa parecida, si bien, la "fase río" tiene un mayor desarrollo. Se invierte más tiempo en la elección de la morfología y calidad del soporte y en su acondicionamiento y descortezado previo. Las fases de plena producción y consumo se desarrollan en el interior de la cavidad (Fig. 3).

La gestión bifacial centrípeta puede diferenciarse visiblemente en función de la materia empleada. Los tres núcleos de sílex registrados, adscritos al método levallois, están completamente agotados (76, 6 y 2 g). En cuarcita, se ha registrado un núcleo levallois con una fractura longitudinal accidental (102 g), un núcleo discoide agotado (92 g) y una espesa lasca con un somero trabajo bifacial jerarquizado (113 g). La estrategia de producción de esta última bien podría ser aquella que definiremos como preferencial inicial.

En términos generales, los productos derivados de los sistemas bifaciales centrípetos cuentan con talones lisos o multifacetados. Su anverso suele estar libre de córtex y muestran negativos en diferentes direcciones. Entre los productos discoides predominan los de relación ortogonal (destacando varias puntas pseudolevallois). Los de relación centrípeta se congregan en las lascas predeterminadas levallois, donde incluimos dos puntas, una de sílex y otra de cuarcita. Los subproductos de ambos modelos, en cuarcita, suelen mostrar restos de corteza. En cambio, sus talones son lisos o bifacetados. En todos estos productos y estrategias de talla, es habitual la captura intencional de flancos de núcleo, en ocasiones apurando restos de corteza.

Según materias primas, primero señalamos que todas las lascas de sílex recuperadas han sido producidas en modalidades bifaciales centrípetas. El soporte de partida, presumiblemente, son fragmentos o grandes lascas obtenidas en los depósitos primarios. En las lascas de cuarcita adscritas a estas modalidades es más difícil determinar el tipo de soporte originario, aunque no descartamos que parte procedan de matrices sobre lasca, sobre todo si establecemos alguna relación entre los modelos levallois y discoide y el preferencial inicial.

Esta última estrategia de reducción, descrita a partir de lascas, consiste en la explotación de una gran lasca o de parte de un canto fragmentado por diaclasas. Se aprovecha o prepara una plataforma de golpeo lisa y, posteriormente, se extraen algunas lascas para acondicionar someramente la cara de explotación (búsqueda de convexidades). En un segundo momento, se extraen algunos productos preferenciales que, además, suelen capturar flancos abruptos (corticales o no). Es probable que esta estrategia de talla no tenga entidad como tal, correspondiendo a la fase inicial de otros sistemas de producción. Precisamente la estructura tipométrica de las lascas de este sistema está más en consonancia con los modelos bifaciales centrípetos que con el longitudinal (Fig. 4).

Las cadenas operativas de todos los esquemas bifaciales centrípetos comparten un elevado control de la calidad y morfología de los soportes de partida. En el sílex llama la atención la variedad de coloraciones, indicativa de un buen conocimiento del territorio de explotación. Tanto en los productos como en las matrices sobresale la gestión levallois: los núcleos están muy agotados y el utillaje procede de fases de plena de producción. Esta insistencia en productos finales contrasta con los escasísimos subproductos (Tab. 1). Es evidente que estamos ante una estrategia de producción cuya secuencia es operada regionalmente, habida cuenta de que en la "fase cueva" únicamente se abandonan fragmentos aislados $\mathrm{y}$ finales de diferentes fases de plena producción y,

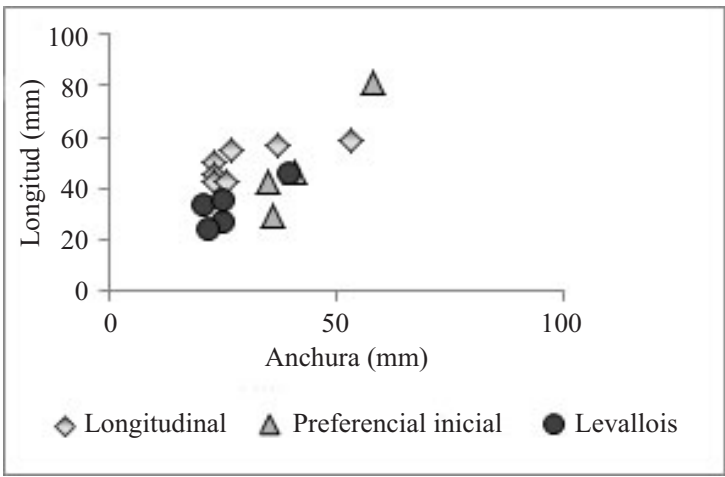

Fig. 4. Diagrama de dispersión (longitud y anchura) en útiles de cuarcita según estrategias de talla de Cueva Corazón (Mave, Palencia), yacimiento del Musteriense antiguo. 
sobre todo, fases de consumo: a saber, núcleos agotados y objetos acabados (Fig. 3).

En cuarcita (de grano medio y fino) consideramos dos estrategias de producción (levallois y discoide), sin descartar su solapamiento. Cada sistema está representado por un núcleo, abandonados por fractura o agotamiento. Entre las lascas, de nuevo, sobresale el utillaje, aunque a diferencia del sílex encontramos más lascas de acondicionamiento y semidescortezado. En este caso es difícil determinar a cuál de las dos estrategias responden. Hemos detectado bastante más utillaje levallois que discoide: en concreto, más lascas predeterminadas que puntas pseudolevallois (Tab. 2).

Resumiendo, en la "fase cueva" aparecen fragmentos aislados de fases de producción y consumo. Este hecho nos sugiere la siguiente secuencia: a Cueva Corazón llegan núcleos de cuarcita formateados o en estadios avanzados de pro-

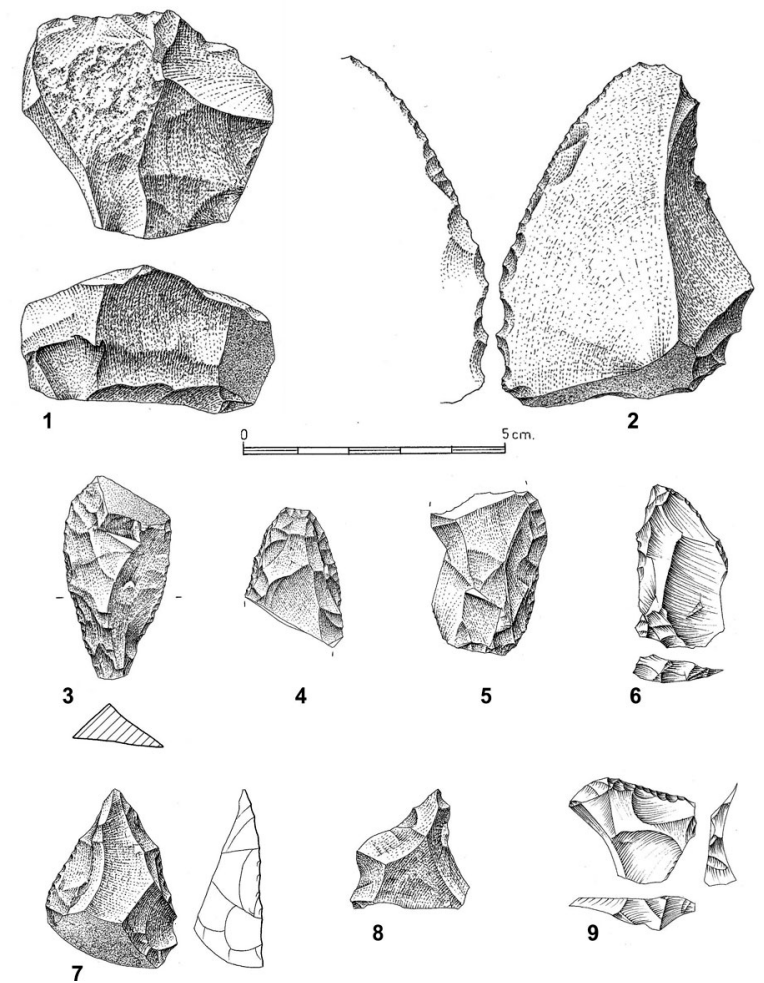

Fig. 5. Instrumental lítico de Cueva Corazón (Mave, Palencia), yacimiento del Musteriense antiguo: Núcleo de cuarcita bifacial jerarquizado sobre lasca (1); raederas de cuarcita $(2,3,4,5)$; punta de cuarcita $(7)$; perforador + denticulado (8); punta levallois en sílex (6); punta pseudo-levallois en sílex con retoques de uso (9). ducción bifacial centrípeta; se abandonan restos de talla y algunos productos acabados y salen aquellas matrices que todavía son productivas y algunos utensilios (Fig. 3).

Es probable que se introduzca en la cueva utillaje de cuarcita generado bajo estos esquemas operativos más complejos. Precisamente, el transporte de objetos acabados en la "fase río" y (re)utilizados en la "fase cueva" puede ser uno de los objetivos de la estrategia de producción preferencial inicial, aunque posteriormente se reconvierta en una gestión bifacial centrípeta.

La peculiaridad más significativa del registro lítico estudiado (Fig. 5) es la abultada representación de productos finales $(50 \%$ de las lascas y $34,6 \%$ del total). Esta sobrerrepresentación del utillaje y, por ende, de la fase de consumo, contrasta con la ausencia de buena parte de los elementos base de la producción. A pesar de la reducida muestra con la que trabajamos y aunque tampoco debe relacionarse unívocamente al utillaje con la fase de consumo (Baena et al. 2004: 120), la circunstancia descrita nos parece suficientemente elocuente para confirmar una significativa fragmentación de las cadenas operativas.

Hasta aquí, una primera aproximación a la caracterización técnica y definición de las cadenas operativas del registro lítico documentado en Cueva Corazón. Conforme se vaya ampliando se podrá ir desbrozando y detallando la secuencia presentada, que será mejor entendida una vez se realicen estudios litológicos y, entre otras cosas, se determinen las áreas de aprovisionamiento de los materiales. Con todo, algunas cosas podemos sugerir, sobre todo si reparamos en la estructura de las cadenas operativas, en la variedad de materias de buena calidad y en la destacada presencia de utillaje. Según apuntó Geneste (3), durante el Musteriense, una sobrerrepresentación de productos finales, propio de lugares centrales, está en consonancia con una fuerte secuenciación espacial de la producción; un elevado control de la calidad impuesto en las propias áreas fuente, probablemente localizadas a una distancia considerable; y un extenso, complejo y bien organizado territorio de explotación.

Precisamente en Cueva Corazón la mayor inversión energética en la captación de materiales

(3) Geneste, J.M. 1985: Analyse lithique d'industries Mousteriennes $d u$ Perigord. Une approche technologique du comportament des groups humaines au Paleolithique Moyen. Tesis Doctoral inédita. Université de Bordeaux. Bordeaux. 
(variados y de buena calidad) está asociada a las estrategias de producción más exigentes que, a su vez, son las más fragmentadas. En suma, la estructuración de las cadenas operativas desenvueltas en este enclave apuntan hacía un comportamiento económico programado espacialmente $\mathrm{y}$ amparado por una estrategia territorial bien estructurada y de amplio espectro.

\section{CUEVA CORAZÓN EN SU CONTEXTO REGIONAL}

En la cuenca del Duero durante la segunda mitad del Pleistoceno medio prevalece un ambiente templado y húmedo con algunas fases más frescas de carácter continental, por lo que, en principio, la biocenosis no sufrió importantes modificaciones. En esta dirección, los datos sedimentológicos y paleoecológicos de la Sierra de Atapuerca (4) señalan unas fluctuaciones climáticas atenuadas y una manifiesta estabilidad de las comunidades de micro y macromíferos. La ausencia de aparatos glaciares pre-würmnienses en la Meseta Norte está en sintonía con estos datos. No obstante se trata de elementos orientativos, precisos a nivel local, sobre todo en el caso de Atapuerca cuya ubicación ecológica es muy singular.

En este marco crono-ambiental tiene lugar la mayor intensidad ocupacional registrada en las principales unidades ecológicas (5) de la Meseta Norte durante el Paleolítico. En este escenario de expansión generalizada se crea una matriz tecnológica uniforme, pero flexible, que redunda en una variabilidad de procesos y técnicas fuertemente vinculadas a los ecosistemas de producción. Los conjuntos industriales propios de los valles, de los páramos o los más escasos recuperados en cueva (Castellanos 1986; Díez Martín 2000; Martín Benito 2000; Santonja y Pérez González 1984, 2000-2001) guardan ciertas semejanzas entre sí. En los ambientes de páramo y cueva se puede rastrear con mayor claridad la complejidad tecno-operativa que caracteriza a los grupos humanos que habitan la cuenca del Duero durante

(4) Se puede encontrar una síntesis en Sánchez Yustos, P. 2009. El Paleolítico Antiguo en la cuenca del Duero. Instrumentos teóricos para el desarrollo de un modelo interpretativo de Arqueología Económica. Tesis Doctoral inédita. Universidad de Valladolid. Valladolid.

(5) Sánchez Yustos, P. 2009. Véase nota 4. la segunda mitad del Pleistoceno medio. Consiste en el desarrollo regional de ciertas estrategias de talla, circunstancia que se traduce en esquemas más elaborados de producción y configuración del utillaje. La proliferación de cadenas operativas regionales en las ocupaciones, principalmente en el páramo, en contraposición a las adscritas al medio fluvial, está inequívocamente relacionada con el alejamiento de los asentamientos de las fuentes de aprovisionamiento (Díez Martín y Sánchez Yustos 2005; Díez Martín et al. 2008; Sánchez Yustos y Díez Martín 2010). Esta circunstancia redunda en un transporte de los objetos con un elevado coeficiente de operatividad, siempre vinculados con las estrategias de configuración y explotación más elaboradas: por ejemplo, pequeños bifaces y cadenas levalllois. El volumen, peso y, en última instancia, el diseño formal de los objetos de estos esquemas operativos (matrices y productos) se adecúa a los ritmos de movimiento del patrón de ocupación de un determinado territorio o biotopo.

Este fenómeno de creciente complejidad del Paleolítico Antiguo normeseteño no se estabiliza en cuanto aparece, aproximadamente en el EIO 11, según el Nivel 10 de Gran Dolina (Rodríguez 2004). A partir de las dataciones disponibles en el páramo (6), entre el EIO 8 y 6 los estándares operativos de las estrategias técnicas más elaboradas tienen en este biotopo el punto de mayor anclaje. En contraste, la dinámica técnica de los valles está dominada por cadenas operativas simples y locales con un gran protagonismo del macroutillaje, aunque en algunas series fluviales también se han registrado evidencias de complejidad técnica (Santonja 1995; Santonja y Pérez González 1984, 2000-2001).

En el último tercio del Pleistoceno medio se alargan y multiplican las cadenas operativas, además de generalizarse un conjunto de morfologías estandarizadas que se adecúan mejor a los distintos tiempos de las actividades, cada vez más numerosas y convenientemente programadas espacialmente. Todo ello indica unas pautas territoriales complejas donde la especialización económica comienza a ganar protagonismo.

Tras el último máximo interglaciar (EIO 5e) en la cuenca sedimentaria de la Meseta Norte apenas se documentan yacimientos. En las terrazas bajas casi no se reconocen industrias paleolí-

(6) Sánchez Yustos, P. 2009: 1274. Véase nota 4. 
ticas. El grueso de ocupación en este medio se debe situar entre el EIO 13 y 6 (Santonja y Pérez González 2000-2001: 68). Entre los escasos yacimientos al aire libre documentados en el último ciclo glaciar, aparte de series aisladas localizadas en depósitos de gravas, destacan los relacionados con importantes afloramientos en sílex como los del Arlanzón en las proximidades de la Sierra de Atapuerca (7) (Navazo et al. 2005) o los de Mucientes en el bajo Pisuerga (Sánchez y Díez 2006-07). En ambas regiones también se han registrado conjuntos que han sido incluidos en la transición Paleolítico Medio/Superior o directamente se han catalogado como postmusterienses (Mosquera et al. 2007; Martín Santamaría et al. 1986).

Las cinco dataciones obtenidas en el páramo coinciden con el lapso temporal mencionado anteriormente (Sánchez Yustos y Díez Martín 2010). Este repentino declive de yacimientos en el interior de la Meseta no se corresponde exclusivamente con problemas de conservación derivados del proceso de vaciado de la propia cuenca. También hay que tener en cuenta cuestiones de orden ocupacional y territorial. Esta hipótesis está reforzada por el hecho de que, a partir del Pleistoceno superior (durante el EIO 5 y 3), se documentan numerosos yacimientos en cuevas localizadas en el borde nororiental de la cuenca, como las de Corazón, La Ermita, Millán, Valdegoba, La Mina y Prado Vargas, cuyas colecciones líticas han sido catalogadas como musterienses (Santonja y Querol 1981; Moure y García 1983; Díez y Navazo 2005; Díez et al. 2008).

Todo ello parece indicar que durante el Pleistoceno superior las poblaciones neandertales se retraen hacia los bordes premontanos de la Meseta. En estas regiones (ecotonos) la diversidad de estratos ecológicos es más variada, por lo que en momentos de rigor climático funcionan como auténticas "áreas refugio". Uno de los escenarios posibles para explicar este hecho puede ser el recrudecimiento de las condiciones climáticas en el último tercio del Riss y el consiguiente deterioro de la biocenosis, sometida a cierto estrés tras cientos de miles de años de ser explotada por unos grupos humanos cada vez más numerosos y

(7) Navazo Ruiz, M. 2006. Sociedades cazadoras-recolectoras en la Sierra de Atapuerca durante el Paleolítico Medio: patrones de asentamiento y estrategias de movilidad. Tesis Doctoral. Universidad de Burgos. Burgos. especializados. La población neandertal, junto con la comunidad biótica que ocupa el interior de la Meseta, comienza a replegarse hacia la periferia. De ello se deduce que las campiñas y los páramos resultan ser las unidades ecológicas más deterioradas al final del EIO 6. La inestabilidad ambiental persistente tras el último ciclo glaciar propicia que, durante las fases cálidas, la comunidad biótica no disponga de tiempo suficiente para recolonizar la región central de la cuenca, donde empiezan a dominar frías praderas de gramíneas y herbáceas estépicas (Rivera 2004: 49). De tal manera, durante el último ciclo glaciar encontramos una Meseta desolada y únicamente en momentos puntuales interpleniglaciares pudieron efectuarse tímidas exploraciones en su interior desde los refugios montanos donde la población neandertal permanece replegada hasta su extinción. A la postre, con el desmantelamiento de las masas polares de la última glaciación y el consiguiente óptimo climático (c. 16,5 ka AP) los primeros grupos de Homo sapiens comienzan a visitar esporádica y estacionalmente refugios en altura en los rebordes montañosos de la Meseta (Delibes y Díez Martín 2006).

La consolidación del poblamiento en la cornisa cantábrica coincide con el límite Pleistoceno medio/superior (Montes 2003; Rodríguez Asensio y Arrizabalaga 2004), cuando las comunidades que habitan la cuenca del Duero empiezan a replegarse hacia la periferia. No obstante, es posible que las primeras ocupaciones de la región cantábrica se remonten a algún momento indeterminado de la segunda mitad del Pleistoceno medio (Montes 2003; Rodríguez Asensio y Arrizabalaga 2004), coincidiendo con el momento de máxima expansión colonizadora de la Meseta Norte.

Los niveles más antiguos de la secuencia de Lezetxiki (Niveles VI y Vb) (Arrasate, Gipúzcoa) podrían corresponder a esta primera etapa de tímida exploración de la cornisa cantábrica (Baldeón 1993), aunque las amplias horquillas cronológicas de las dataciones obtenidas impiden precisar a este respecto (Falguéres et al. 2005-06). El tramo inferior de la secuencia de El Castillo (Niveles 26-24) (Puente Viesgo, Cantabria) está enmarcado en el EIO 5. Las dataciones realizadas por Uranio/Thorio en el Nivel 23 Costra son $89+11-10$ ka AP y 92,8 ka AP (Bishoff et al. 1992; Cabrera y Bernaldo Quirós 2000). Las industrias de los Niveles 25 y 24 de estos depósitos 
son asignadas a una etapa antigua del Musteriense, mientras que el Nivel 26 es considerado Achelense final (Montes 2003). En la cercana Cueva de Cavalejos (Piélagos, Cantabria) sucede algo muy parecido. Bajo el Nivel 12 Costra, datado por U/Th. en $91 \mathrm{ka} A P$, se registran dos niveles con materiales arqueológicos. El Nivel 13, con escasos efectivos líticos y paleontológicos, aparentemente, es un nivel Musteriense antiguo. Sin embargo, los escasísimos restos del Nivel 15 (de más de $101 \mathrm{ka}$ AP según datación por U/Th.) son considerados del Paleolítico Antiguo (Sanguino y Montes 2005). En las fases iniciales del Pleistoceno superior o en los últimos episodios del Pleistoceno medio, al igual que en la cuenca del Duero (donde un buen ejemplo podría ser el yacimiento salmantino de La Maya I), en la región cantábrica todavía es posible encontrar conjuntos líticos arcaicos (8). Estas evidencias se suelen corresponder con ocupaciones al aire libre y, genéricamente, se catalogan como "Achelense superior". Se caracterizan por una simplicidad de los procesos técnicos de producción; una alta uniformidad, que se traduce en una escasa variabilidad técnica y morfológica; una baja especialización funcional, y una notable inmediatez en el aprovisionamiento, transformación, uso y abandono de materiales y objetos (Montes 2003).

En medio de esta interesante coyuntura territorial y tecnológica debemos enmarcar Cueva Corazón. $\mathrm{Su}$ indudable filiación musteriense y una datación muy similar a las obtenidas en los niveles inferiores de El Castillo y Covalejos parecen confirmar la hipótesis de que la tecnología musteriense emerge en la región central de la cornisa cantábrica durante los primeros compases del EIO 5 (Montes 2003; Rodríguez Asensio y Arrizabalaga 2004). Es posible plantear un hipotético proceso migratorio Sur-Norte (Meseta-Cordillera) en función de la mayor antigüedad de este tipo de industrias en la cuenca del Duero. Como hemos visto, su génesis se remonta al EIO 11, aunque su generalización se produce a partir del EIO 8, en gran medida, gracias a la ocupación de un determinado biotopo meseteño: el páramo.

(8) En el valle de Campoo (Cantabria), a $30 \mathrm{~km}$ de Cueva Corazón, se han documentado varios conjuntos líticos arcaicos en medio fluvial. Uno de ellos, Espilla, ha proporcionado dataciones absolutas por TL muy próximas a Cueva Corazón: $94660 \pm 7706$ ka AP (Gutiérrez Morillo y Serrano Cañadas 2007).

\section{CONCLUSIONES Y DISCUSIÓN}

La Meseta Norte, "sin duda, constituye el área peninsular con mayor número y calidad de estudios sobre el Paleolítico Inferior" (Montes 2003: 64). Los yacimientos de la Sierra de Atapuerca han puesto al descubierto la gran antigüedad del primer poblamiento y la amplísima secuencia ocupacional de estos territorios. La intensa labor de prospección y excavación realizada en el resto de la cuenca ha servido para determinar con mayor precisión el proceso de complejidad creciente de las formaciones socio-económicas durante el Paleolítico Antiguo. La cornisa cantábrica es una de las regiones de Europa con más yacimientos musterienses cuya calidad le ha convertido a esta región en un lugar de referencia para comprender las sociedades neandertales del último ciclo glaciar.

La cronología y posición estratégica de la Cueva Corazón le convierten en un enclave excepcional para conocer la complejidad técnica y la especialización económica que protagonizan los grupos humanos del Pleistoceno superior inicial, un período escasamente registrado en las secuencias cántabras y muy mal representado en la cuenca del Duero.

La incipiente intervención arqueológica acometida en esta cavidad impide precisar las estrategias de talla, más allá de su mera detección y descripción. Tampoco se puede detallar con mucho rigor la funcionalidad de este enclave, por lo menos hasta que estén disponibles los datos paleoecológicos y zooarqueológicos. No obstante, como apunta Carrión et al. (2008: 305), una fragmentación y diversidad de cadenas operativas suele ser indicativo de lugares referenciales. $\mathrm{Pa}$ rece evidente que el registro lítico de Cueva Corazón responde a un conjunto de ocupaciones ricas y complejas técnica y funcionalmente. Hemos tenido oportunidad de comprobar cómo las estrategias operativas más sofisticadas están asociadas a unos patrones de captación de calidades y morfologías cuidadosamente programados dentro de una elaborada trama regional. Todo ello es síntoma inequívoco de una lógica ocupacional compleja y bien estructurada, así como de una inherente complejidad de las redes territoriales y sociales.

Más allá de estos importantes apuntes socioeconómicos, Cueva Corazón nos remite a otras cuestiones de mayor calado. Nos invita a refle- 
xionar y preguntarnos sobre el origen del Musteriense en la Región Cantábrica: ¿Es el Achelense cantábrico el sustrato a partir del cual se forma el Musteriense cantábrico?, tal y como se está sugiriendo (Rodríguez Asensio y Arrizabalaga 2004: 59). Indudablemente, tras la entrada de Cueva Corazón en el escenario cantábrico este debate se ha reabierto. Dado el estado de la cuestión, no parece tan improbable que grupos neandertales de la Meseta Norte, con tecnología musteriense, accedan a la región central de Cantabria a través del corredor natural Pisuerga/alto Ebro/cuencas centrales (ríos Besaya y Pas). En este segmento geográfico se localizan Cueva Corazón, El Castillo y Covalejos, así como los numerosos yacimientos de la Marina de Santander y sierras litorales aledañas. Si admitimos esta última hipótesis (para nada definitiva), debemos contemplar la posibilidad de que en la región central de Cantabria, al inicio del Pleistoceno superior, pudieran convivir dos grupos humanos claramente diferenciados cultural y económicamente: los achelenses y los musterienses. Más allá de las obvias diferencias tecno-tipológicas entre ambos tecnocomplejos (culturas), también son muy significativas las diferencias observadas en relación a las estrategias de adquisición de los recursos líticos, lo que indudablemente conlleva una serie de importantes implicaciones económicas (Montes y Sanguino 1998).

Recientemente, en Cantabria estas diferencias tecno-tipológicas se han interpretado en el marco de un lógico proceso evolutivo (transición de una facies a otra) y/o en función de diferentes estrategias empleadas en los yacimientos al aire libre con respecto a los documentados en cueva (Rodríguez Asensio y Arrizabalaga 2004; Montes 2003). En esta misma región la variabilidad del musteriense se ha explicado mediante el "libre albedrío técnico" que estos grupos operan en función de los lugares en los que se encuentran, asociando así determinadas expresiones técnicas a un determinado marco eco-espacial (Baena et al. 2005: 473; Carrión et al. 2008). En la cuenca del Duero también hemos elaborado interpretaciones de corte ambiental y económico para explicar las diferencias tecno-tipológicas observadas entre los yacimientos en páramo y los coetáneos yacimientos registrados en los depósitos aluviales de los cercanos valles (Díez Martín 2000; Sánchez Yustos y Díez Martín 2010). Pero, tras lo dicho, no descartamos la necesidad de una reinterpretación de la variabilidad del Paleolítico Antiguo en función de parámetros (culturales) en gran medida superados $-\mathrm{y}$ hasta olvidados.

En definitiva, es un buen momento para retomar un fructífero debate y una interesante relación entre dos importantes regiones de la geografía peninsular. En este punto, Cueva Corazón se posiciona como uno de los goznes a partir del cual diseñar marcos interpretativos e hipótesis de trabajo que deben ser contrastadas y validadas en ambos lados de la cordillera cantábrica.

\section{BIBLIOGRAFÍA}

Alcalde Crespo, G. 1992: La Montaña palentina. Tomo I, La Lora. Merino. Palencia.

Baena, J.; Carrión, E.; Ruiz, B.; Ellwood, B.; Sesé, C.; Yravedra, J.; Jordá, J.; Uzquiano, P.; Velázquez, R.; Manzano, I.; Sánchez Marco, A. y Hernández, F. 2005: "Paleoecología y comportamiento humano durante el Pleistoceno Superior en la comarca de la Liébana: la secuencia de la Cueva de El Esquilleu (Occidente de Cantabria, España)". En J. A. Lasheras Gurruchaga y R. Montes Barquín (eds.): Neandertales cantábricos. El estado de la cuestión. Monografías XX, Museo Nacional y Centro de Investigación de Altamira. Madrid: 461-487.

Baena, J.; Cabrera, V. y Carrión, E. 2004: "Las sociedades neandertales durante el final del Paleolítico Medio". Kobie 8: 91-140.

Baldeón, A. 1993: "El yacimiento de Lezetxiki (Guipúzcoa, País Vasco). Los niveles musterienses". Munibe 45: 3-97.

Bischoff, J. A.; García, J. F. y Strauss, L. G. 1992: "Uranium-Series Isochron dating at E1 Castillo Cave (Cantabria, Spain). The Acheulean/Musterian question". Journal of Archaeological Science 19 (1): 49-62.

Cabrera, V. y Bernaldo de Quirós, F. 2000: Excavaciones arqueológicas en la Cueva del Castillo (Puente Viesgo). Actuaciones Arqueológicas en Cantabria, 1984-1999. Consejería de Cultura y Deporte de Cantabria. Santander.

Castellanos, P. 1986: El Paleolítico Inferior en la Submeseta Norte. Excma. Diputación Provincial de León. Institución Fray Bernardino de Sahagún. CSIC; CECEL. León.

Carrión, E.; Baena, J.; Conde Ruiz; Cuartero, F. y Roca, M. 2008: "Variabilidad tecnológica en el Musteriense de Cantabria". Treballs d'Arqueología 14: 279-318.

Delibes, G. y Díez Martín, F. 2006: “¿Una Meseta desolada? Estado actual de la investigación sobre el Paleolítico Superior en las regiones interiores de la Península Ibérica”. En G. Delibes de Castro y 
F. Díez Martín (eds.): El Paleolítico superior en la Meseta Norte Española. Studia Archaeologica 94. Valladolid: 11-40.

Díez, C. y Navazo, M. 2005: “Apuntes sociales y geográficos a partir de los yacimientos del Paleolítico Medio en la zona nororiental de la Meseta Castellano Leonesa". En J. A. Lasheras Gurruchaga y R. Montes Barquín (eds.): Neandertales cantábricos. El estado de la cuestión. Neandertales cantábricos. El estado de la cuestión. Monografías XX, Museo Nacional y Centro de Investigación de Altamira. Madrid: 1-54.

Díez, C.; Alonso, R.; Bengoechea, A.; Colina, A.; Jordá, J. F.; Navazo, M.; Ortiz, J. E.; Pérez, S. y Torres, T. 2008: "El Paleolítico Medio en el Valle del Arlanza (Burgos). Los sitios de La Ermita, Millán y La Mina". Cuaternario y Geomorfologia 22 (3-4): 135-157.

Díez Martín, F. 2000: El poblamiento paleolítico en los páramos del Duero. Servicio de Publicaciones de la Universidad de Valladolid. Valladolid.

Díez Martín, F. y Sánchez Yustos, P. 2005. "Asentamientos paleolíticos en los páramos de la Meseta Norte Española. Hacia la construcción de un modelo predictivo de territorialidad en la Cuenca del Duero". Actas del IV Congreso de Arqueología Peninsular (Faro, Portugal 2004): 251-266.

Díez Martín, F.; Sánchez Yustos, P.; Gómez González, J. A. y Gómez de la Rua, D. 2008: "Earlier Palaeolithic Settlement Patterns: Landscape Archaeology on the river Duero Basin Plateaus (Castilla y León, Spain)". Journal of World Prehistory 21: 103-137.

Falguères, C.; Yokohama, Y. y Arrizabalaga, A. 2005-2006: "La geocronología del yacimiento pleistocénico de Lezetxiki (Arrasate, País Vasco). Crítica a las dataciones existentes y algunas nuevas aportaciones". Munibe 57 (2): 93-106.

Gutiérrez Morillo, A. y Serrano Cañadas, E. 2007: "Nuevas aportaciones al estudio del paleolítico medio en el valle de Campoo (Cantabria): aproximación cultural, cronológica y geomorfológica”. En J. M. Maillo y E. Baquedano (eds.): Miscelánea en homenaje a Victoria Cabrera. Zona Arqueológica 7 (2). Alcalá de Henares: 234-251.

Martín Benito, J. L. 2000: El Achelense en la cuenca media occidental del Duero. Instituto de Estudios Zamoranos Florían de Ocampo. Zamora.

Martín Santamaría, E.; Rojo, A. y Moreno Asenjo, M. A. 1986: "Hábitat postmusteriense en Mucientes (Valladolid)". Numantia II: 87-99.

Montes Barquín, R. 2003: El primer poblamiento de la Región Cantábrica. El Paleolítico Inferior Cantábrico. Monografías del Museo Nacional y Centro de Investigación de Altamira 18. Madrid.

Montes Barquín, R. y Sanguino González, J. 1998: "Diferencias en las estrategias de adquisición de re- cursos líticos entre el Paleolítico Inferior y Medio en el centro de la Región Cantábrica”. En J. Bernabeu, T. Orozco, X. Terradas (eds.): Los recursos abióticos en la Prehistoria. Caracterización, aprovechamiento e intercambio. Universitat de Valencia. Valencia: 55-71.

Mosquera, M.; Ollé, A.; Pérez González, A.; Rodríguez, X. P.; Vaquero, M.; Vergés, J. M. y Carbonell, E. 2007: "Valle de las Orquídeas: un yacimiento al aire libre del Pleistoceno Superior en la Sierra de Atapuerca (Burgos)". Trabajos de Prehistoria 64 (2): 143-155.

Moure Romanillo, A. y García Soto, E. 1983: "Cueva Millán y La Ermita. Dos yacimientos musterienses en el valle medio del Arlanza". Boletín del Seminario de Estudios de Arte y Arqueología XLIX: 5-29.

Navazo, M.; Díez, C.; Torres, T.; Colina, A. y Ortiz, J. E. 2005: "La cueva de Prado Vargas. Un yacimiento del Paleolítico Medio en el sur de la cordillera cantábrica”. En J. A. Las Heras Gurruchaga y R. Montes Barquín (eds.): Neandertales cantábricos. El estado de la cuestión. Monografías del Museo Nacional y Centro de Investigación de Altamira 20. Madrid: 151-166.

Rivera, A. 2004: "Paleoclimatología y cronología del Würn reciente: un intento de síntesis". Zephyrus 57: 27-53.

Rodríguez, X. P. 2004: "Atapuerca y el inicio del Paleolítico medio en Europa". En E. Baquedano y S. Rubio Jara (eds.): Zona Arqueológica IV. Miscelánea en Homenaje a Emiliano Aguirre. Museo Arqueológico Regional. Alcalá de Henares: 416-431.

Rodríguez Asensio, J. A. y Arrizabalaga, A. 2004: “El poblamiento más antiguo de la región: las ocupaciones previas al IS4. Desde el inicio del poblamiento a circa 80.000 AP". Kobie 8: 51-90.

Sánchez Yustos, P. y Díez Martín, F. 2006-07: "Historia de las investigaciones paleolíticas en la provincia de Valladolid. El caso Mucientes". Boletín del Seminario de Estudios de Arqueología LXII-LXXIII: 7-38.

Sánchez Yustos, P. y Díez Martín, F. 2010: "El Paleolítico Antiguo en la Cuenca del Duero: La Unidad Ecológica de Páramo". Zephyrus LXVI: 39-56.

Sanguino González, J. y Montes Barquín, R. 2005: "Nuevos datos para el conocimiento del Paleolítico Medio en el centro de la Región Cantábrica: La Cueva de Covalejos". En J. A. Lasheras Gurruchaga y R. Montes Barquín (eds.): Neandertales cantábricos. El estado de la cuestión. Monografías del Museo Nacional y Centro de Investigación de Altamira 20. Madrid: 489-538.

Santonja, M. 1995: "El Paleolítico inferior en la Submeseta Norte y en el entorno de Atapuerca. Balance de los conocimientos en 1992”. En J. M. Bermú- 
dez de Castro, E. Carbonell y J. L. Arsuaga (eds.): Actas del Congreso Evolución Humana en Europa y los yacimientos de la Sierra de Atapuerca (Valladolid, 1992) 2: 421-444. Valladolid.

Santonja, M. y Querol, M. A. 1981: "Indicios del Paleolítico Inferior y Medio en la provincia de Palencia". Numantia I: 167-170.

Santonja, M. y Pérez González, A. 1984: Las industrias paleolíticas de La Maya I en su ámbito regional. Ministerio de Cultura, Dirección General de
Bellas Artes y Archivos. Subdirección General de Arqueología y Etnografía. Madrid.

Santonja, M. y Pérez González, A. 2000-2001: “El Paleolítico Inferior en el interior de la Península Ibérica. Un punto de vista desde la geoarqueología”. Zephyrus 53-54: 27-77.

Santonja Gómez, M.; Santonja Alonso, M. y Alcalde, G. 1982: "Aspectos de la ocupación humana antigua del Cañón de la Horadada (Palencia)". Publicaciones de la Institución Tello Téllez de Meneses 47: 337-392. 